\title{
ASPECTOS TÉCNICOS, CONCEITUAIS E POLÍTICOS DO SURGIMENTO E DESENVOLVIMENTO DO PROGRAMA ESPORTE E LAZER DA CIDADE
}

\author{
Fernando Augusto Starepravo \\ Universidade Estadual de Maringá, Maringá, Paraná, Brasil \\ Wanderley Marchi Júnior \\ Universidade Federal do Paraná, Curitiba, Paraná, Brasil
}

\begin{abstract}
Resumo
No presente artigo buscamos analisar o processo de implementação e desenvolvimento do Programa Esporte e Lazer da Cidade (PELC), considerando seus aspectos técnicos, conceituais e políticos, ressaltando os avanços, limites e contradições inerentes ao PELC, tendo em vista o espaço social de sua produção, o subcampo político/burocrático do esporte e lazer. Para tanto, recorremos a entrevistas semiestruturadas com agentes gestores do Ministério do Esporte diretamente relacionados ao processo de criação, implementação e desenvolvimento do PELC, bem como a análise documental de alguns documentos do ministério relativos ao PELC. Sustentamos que o PELC se difere de outros programas esportivos sociais por ter sido concebido a partir de experiências oriundas do subcampo cientifico/acadêmico das políticas públicas de esporte e lazer e das experiências de gestões municipais do Partido dos Trabalhadores (PT), e desenvolvido sob a égide de uma disputa política entre os dois partidos que administraram o Ministério do Esporte.
\end{abstract}

Palavras-chave: Políticas públicas. Esportes. Atividades de Lazer. Política.

\section{Introdução}

$\mathrm{O}^{2}$

Programa Esporte e Lazer da Cidade (PELC) trata-se de um programa do tipo finalístico, de responsabilidade do Ministério do Esporte. Uma breve visita ao site do ministério nos mostra que o programa busca,

[...] suprir a carência de políticas públicas e sociais que atendam às crescentes necessidades e demandas da população por esporte recreativo e lazer, sobretudo daquelas em situações de vulnerabilidade social e econômica, reforçadoras das condições de injustiça e exclusão social a que estão submetidas (BRASIL, 2010, n. p.). 
Esse primeiro contato com o programa através de um meio público de divulgação da informação, todavia, nos fornece informações limitadas, uma vez que seus objetivos não diferem substancialmente de tantos outros programas esportivos sociais desenvolvidos no país por órgãos governamentais e não-governamentais. Contentar-se apenas com as informações oficialmente publicizadas, porém, pode nos colocar no campo das incertezas e limitações interpretativas, numa leitura de viés simplista, próxima ao senso comum. Como pesquisadores e profissionais da área de educação física, esporte e lazer, devemos buscar o aprofundamento sobre questões que dizem respeito ao nosso dia-a-dia de trabalho, pesquisa e intervenção. Nesse caso, de um programa esportivo social, de grande repercussão nacional, que guarda consigo uma história única de desenvolvimento de quase dez anos, desenhada no bojo de um espaço político de muitas disputas e contradições.

Pretendemos aqui ampliar a compreensão sobre o PELC, por meio de uma análise do processo de implementação e desenvolvimento do PELC, considerando seus aspectos técnicos, conceituais e políticos, ressaltando os avanços, limites e contradições inerentes ao programa. Apesar de o PELC ter sido objeto de estudo de vários autores do subcampo científico/acadêmico das políticas públicas de esporte e lazer (AREIAS et al., 2009; COSTA JÚNIOR, 2009; EWERTON; FERREIRA, 2009; FIGUEIREDO, 2009; HÚNGARO; MELO, 2007; LIÁO JÚNIOR; SAMPAIO; BEHMOIRAS, 2009; MENDES, 2009; SAGRILLO; BACCIN; BOTH, 2007; SUASSUNA, 2009), entendemos que tais reflexões, para além das análises empreendidas, nos remeterão ao entendimento mais aprofundado do espaço social de produção das políticas públicas de esporte e lazer, o "subcampo político/burocrático do esporte e lazer no Brasil"". Sustentamos que o

1-Um espaço que supõe a dissociação da posição e de seu ocupante, da função e do funcionário, do interesse público e dos interesses privados, mas que paradoxalmente funciona como um metacampo do poder, até porque a gênese da ordem pública vem acompanhada da aparição e acumulação de um "capital público" (BOURDIEU, 2005). Cada área no interior do campo político/burocrático, por sua vez, pode ser entendida como um subcampo político/burocrático, onde as especificidades da área de atuação do Estado delimitam o espaço social de atuação dos agentes a ela vinculados. Nesse caso nos referimos ao subcampo político/burocrático do esporte e lazer, constituído na década de 1940 no Brasil, e que recentemente tem experi- 
PELC se difere de outros programas esportivos sociais por ter sido concebido a partir de experiências oriundas do "subcampo cientifico/acadêmico das políticas públicas de esporte e lazer"2 e das experiências de gestões municipais do Partido dos Trabalhadores (PT), e desenvolvido sob a égide de uma disputa política entre os dois partidos que durante anos administraram o Ministério do Esporte (Partido Comunista do Brasil - PCdoB e PT), garantindo a ele um caráter distintivo em termos de políticas públicas de esporte e lazer.

Tal empreitada se justifica, dentre outros motivos, pela escassez de trabalhos na área de políticas públicas de esporte e lazer que tratem da dimensão arena política ${ }^{3}$ no Brasil e no entrelaçamento de duas dimensões políticas (AMARAL; PEREIRA, 2009). Entendemos que o presente artigo transita entre a dimensão conceitual (normativa) e a implementação da política governamental.

Como metodologia, recorremos a entrevistas semi-estruturadas com agentes gestores do Ministério do Esporte diretamente relacionados ao processo de criação, implementação e desenvolvimento do PELC, que ocuparam cargos de segundo e terceiro escalão na estrutura administrativa do ministério. A escolha dos sujeitos foi intencional

mentado uma série de mudanças estruturais, especialmente a partir da criação do Ministério do Esporte.

2-Espaço social (campo ou subcampo) de produção científica. No caso brasileiro, pode-se dizer que esse espaço social se estrutura como um campo científico/acadêmico, lócus de relações, tendo como protagonistas agentes, que têm por delegação produzir conhecimento científico. Apesar de Hey (2008) entender o campo como acadêmico, e não científico, uma vez que no Brasil, tem-se mais presente a idéia de academia, com cada área do conhecimento sendo uma espécie de sociedade de caráter científico e com membros próprios, mas que tem um ethos comum global, admite-se aqui o campo como indissociavelmente acadêmico e científico, uma vez que a produção é científica e o meio onde é produzida é acadêmico. O campo científico/acadêmico é então entendido como o lócus onde ocorrem práticas institucionalizadas de produção do conhecimento, que envolve sobretudo a idéia de universidade. Cada área no interior do campo científico/acadêmico, por sua vez, pode ser entendida como um subcampo científico/acadêmico, onde as especificidades da área delimitam o espaço social de atuação dos agentes a ela vinculados, no caso as políticas públicas de esporte e lazer.

3-Frey (2000, p. 223) define arena política como "processos de conflito e de consenso dentro das diversas áreas de política, as quais podem ser distinguidas de acordo com seu caráter distributivo, redistributivo, regulatório ou constitutivo". 
e considerou como critério o trânsito dos agentes na intersecção dos subcampos científico/acadêmico e político/burocrático. Os gestores são agentes responsáveis pela formulação e implementação de políticas públicas de esporte e lazer, em seu trabalho no Ministério do Esporte, secretarias estaduais e municipais de esporte e lazer, conselhos de esporte e lazer, confederações, ONGs, escolas, entre outros. O foco das entrevistas esteve, portanto nos gestores que têm ou tiveram responsabilidade na condução de políticas públicas no Ministério do Esporte, mas que de alguma forma se aproximam ou transitam no campo acadêmico. Foi entrevistado um total de quatro agentes gestores, entre 25 de março de 2010 e 29 de novembro de 2010. Para garantir o anonimato dos sujeitos de pesquisa não apresentaremos seus nomes, usando códigos para representá-los. Além disso, foi realizada a análise documental de alguns documentos ${ }^{4}$ do Ministério do Esporte relativos ao PELC.

\section{O programa esporte e lazer na cidade}

O PELC teve seu nascimento anunciado, para efeito de presença no PPA 5 2004-2007, denominado "Brasil, um País de Todos", no último instante da data limite estabelecida pelo Ministério do Planejamento para o encaminhamento, por parte dos distintos ministérios, de seus programas orçamentários (CASTELLANI FILHO, 2007), portanto no ano de 2003. Trata-se de um projeto gestionado no interior da extinta Secretaria Nacional de Desenvolvimento do Esporte e Lazer (SNDEL) e hoje sob responsabilidade da Secretaria Nacional de Esporte, Lazer e Inclusão Social (SNELIS).

\footnotetext{
4-Especialmente o conteúdo do sitio digital do Ministério do Esporte e os documentos referentes aos Planos Plurianuais do governo federal do Brasil durante o período pesquisado.

5-De acordo com Veronez (2005), a partir da Constituição de 1988, passa a vigorar no Brasil um novo modelo de planejamento das ações governamentais no nível federal. Trata-se do Plano Plurianual (PPA), cuja lei que o institui estabelece de forma regionalizada, as diretrizes, objetivos e metas da administração pública federal para as despesas de capital ou outras delas decorrentes e para as relativas aos programas de duração continuada. O PPA é um instrumento de planejamento de médio prazo. Suas metas devem ser aplicadas a partir do segundo ano de governo, estendendo-se até o primeiro ano do governo seguinte.
} 
O PELC, em sua proposta, direciona ações que contemplam o esporte recreativo, entre outras atividades inseridas na concepção macro do lazer. As palavras "esporte e lazer", utilizadas no nome do programa, podem ser entendidas através da colocação de Castellani Filho (2007, p. 5), quando ele afirma que "ambas constituem-se em conceitos distintos, porém confluentes, na medida em que o primeiro (esporte), em sua dimensão recreativa, dissociada da busca do rendimento, encontrava no lazer a possibilidade concreta de expressão".

Seus objetivos centrais atualmente são ampliar, democratizar e universalizar o acesso à prática e ao conhecimento do esporte recreativo e de lazer, integrando suas ações às demais políticas públicas, favorecendo o desenvolvimento humano e a inclusão social. Para tanto são três os eixos centrais do PELC:

1. Funcionamento de Núcleos de Esporte Recreativo e de Lazer, nas diversas regiões do Brasil, com o objetivo de garantir o direito ao acesso de qualidade a políticas públicas de lazer e de esporte, em sua dimensão recreativa, para as diversas faixas etárias, garantindo a inclusão de pessoas com deficiência.

2. Funcionamento da Rede CEDES - Centros de Desenvolvimento de Esporte Recreativo e de Lazer junto às Instituições de Ensino Superior - por meio do estímulo e fomento à produção e difusão de conhecimentos científico-tecnológicos, voltados à qualificação das políticas públicas de esporte recreativo e do lazer.

3. Implantação e Modernização de Infra-Estrutura para Esporte Recreativo e Lazer, que prevê a construção e reforma de equipamentos, ação executada pela Secretaria Executiva do Ministério do Esporte (BRASIL, 2010, n. p.).

Observa-se que os três eixos de ação do PELC têm correspondência a algumas dificuldades observadas na construção de políticas públicas de esporte e lazer pela equipe da SNDEL, quando da criação da secretaria. A elaboração do PELC, segundo seus idealizadores, não foi aleatória ou apenas pautada no empirismo, práticas recorrentes no subcampo político/burocrático de esporte e lazer (LINHALES, 1996; VERONEZ, 2005). Foi uma iniciativa baseada em alguns princípios e conceitos oriundos do espaço social antes ocupado por alguns agentes da SNDEL no ministério, o campo científico/acadêmico. 
Pensamos no que um programa guarda-chuva, do ponto de vista das ações, teria que dar conta para efetivamente ser uma política que tivesse como objetivo a universalização do direito ao acesso ao esporte e ao lazer (GESTOR B, 2010).

Sob a lógica do planejamento e orçamento governamental, deveria a SNDEL propor um grande programa (chamado de guarda-chuva pelo gestor), que comportaria em sua rubrica praticamente todas as ações da secretaria, na configuração de ações. Esse grande programa então surgiu configurado de acordo com uma análise situacional, e com base nos procedimentos de um renomado autor do campo acadêmico.

Nesse momento nós nos baseávamos muito num autor [...] do campo do planejamento, que se chamava Carlos Matus [...]. Ele é o precursor do que se chama de planejamento estratégico situacional. O planejamento estratégico dentro do campo governamental. Então nós lidávamos assim com a expressão "nós", que é uma expressão que vem dele. Quais são os "nós" que temos que desamarrar para garantir [...] o acesso universalizado ao esporte e ao lazer? (GESTOR B, 2010)

Os "nós" levantados pela equipe estariam relacionados especialmente a ausência de espaços para a prática esportiva e de lazer. Quando os espaços existiam por vezes estavam com pouca manutenção ou então sucateados. Outro "nó" detectado foi a falta de profissionais com formação para atuar com as políticas públicas de esporte e lazer. "Então o que nós pensamos? Que um programa, além de elaborar, oferecer, manter espaços, construir espaços, teria que ter pessoas capazes de atuar nesses espaços" (GESTOR B, 2010). O PELC então surge como um programa com vistas à superação dos "nós" detectados, buscando dar conta da disponibilidade de espaços, oportunizar práticas, e estimular a reflexão e produção científica sobre o esporte e lazer.

O primeiro eixo para dar conta do "nó" da falta de programas voltados ao esporte e lazer; o segundo para a formação e produção de conhecimento acerca das políticas públicas de esporte e lazer; e o terceiro eixo voltado à carência de espaços públicos e manutenção dos equipamentos de esporte e lazer.

Os três eixos centrais do PELC, por sua vez, foram operacionalizados através de quatro estratégias principais, que por sua vez se desdo- 
bram em ações específicas, com conotação realmente finalística.

A primeira estratégia, que será tratada no presente artigo, é a "Ação Educativa", que busca a formação continuada de gestores, agentes, lideranças comunitárias, pesquisadores, legisladores e outros parceiros atuantes nas esferas públicas federal, estadual e municipal, com vistas à formulação e implementação de políticas públicas de esporte e lazer de inclusão social e cultural (BRASIL, 2011). Para tanto, sua ação específica é o "Funcionamento de núcleos do PELC", em órgãos públicos federais, estaduais, municipais e organizações não-governamentais. As principais metas desta ação são a formação de gestores e lideranças comunitárias, considerando principalmente as possibilidades e importância do desenvolvimento de políticas públicas de esporte e de lazer, a integração comunitária, a elevação da auto-estima dos participantes e o acesso ao esporte e ao lazer como direitos sociais (BRASIL, 2011).

Essa ação, configurada formalmente como projeto ${ }^{6}$, e que constitui o atendimento direto à população, através de uma política social que pretende garantir o acesso dos indivíduos ao esporte e lazer como direitos sociais, é usualmente conhecida como o PELC ${ }^{7}$. Porém, vale relembrar que o PELC foi uma espécie de programa guarda-chuva da SNDEL, que abrange várias ações, dentre elas o Funcionamento de Núcleos do PELC, que será referenciado no texto como "PELC Projeto Social".

\section{PELC projeto social}

O PELC Projeto Social se apresenta como uma ação que atende diretamente a população através da atuação sistemática em núcleos do programa. Surge do ponto de vista técnico, amparado nas experiências de gestões municipais do Partido dos Trabalhadores - PT $^{8}$ (dos qua-

6-Instrumento de programação para alcançar o objetivo de um programa, envolvendo um conjunto de operações, limitadas no tempo, das quais resulta um produto que concorre para a expansão ou aperfeiçoamento da ação do Governo (BRASIL, 2003).

7-No senso-comum e muitas vezes pelos próprios documentos oficiais, causando certa confusão conceitual.

8-Tais experiências foram relatadas pelos gestores entrevistados, como exemplificado nos trechos a seguir:

“[...] princípios administrativos como nós tínhamos, a questão da descentralização,

Pensar a Prática, Goiânia, v. 16, n. 3, p. 619-955, jul./set. 2013 
dros do partido saíram os gestores que estiveram a frente da SNDEL), com o objetivo de proporcionar ao cidadão a efetivação dos direitos ao esporte e ao lazer, tendo como ponto de partida os "nós" detectados pela equipe da SNDEL ao verificar as condições do esporte e do lazer no Brasil.

Frente aos objetivos, o PELC Projeto Social se concretiza através de convênios do Ministério do Esporte com instituições estatais estaduais, municipais e federais, bem como com entidades privadas sem fins lucrativos. Prevê funcionamento de núcleos com atividades esportivas e de lazer numa perspectiva intergeracional (Núcleos do PELC para todas as idades), ou voltadas a grupos específicos (Núcleos do PELC Vida Ativa9 e Núcleos PELC/Pronasci). Quando há necessidade o PELC pode promover a construção e/ou manutenção de espaços para o funcionamento dos núcleos. Além disso, a unidade do programa se estabelece através do processo de formação (debatido por

e aí envolvia a participação do gestor, a criação de um conselho municipal, que participasse da construção das políticas, e que avalizasse o trabalho feito pelo gestor municipal, a questão da transparência administrativa e do controle social, instalação de mecanismos de controle social dos recursos que eram investidos dentro do município. [...] E tudo isso vinha muito de princípios do PT da década de 1980, das gestões petistas ou da frente popular em nível municipal que era basicamente a nossa experiência. A gente queria levar essa experiência que a gente tinha em nível municipal para o nível nacional. Uma coisa muito interessante. O próprio Esporte e Lazer da Cidade ele surge como uma idéia de um programa que nós fizemos aqui na época do prefeito. Que nós tínhamos aqui na cidade de Pelotas 'Pelotas, cidade com mais esporte', e um outro programa era 'Pelotas, cidade com mais lazer"' (GESTOR B, 2010).

"Então o programa-chave nosso chama-se PELC (Programa Esporte e Lazer da Cidade). Esse programa foi construído sob um olhar de alguns municípios e estados, pouco menos ainda, que tinham desempenhado uma função no seu cotidiano de gestão municipal que dava conta de algumas respostas para o cidadão. [...] Então ele não foi assim ó, sonhado e concebido num gabinete, agora temos um plano para a nação. Não! Foi uma série de experiências bem sucedidas, em vários estados do país. Citaria entre elas Porto Alegre, Caxias do Sul, alguma cidades do ABC, Diadema, Santo André, no Recife, Belém do Pará, estado do Mato Grosso do Sul" (GESTOR C, 2010).

9-Há a impressão nesse caso que o aspecto político prevaleceu sobre o técnico quando se criou uma forma de atuação voltada especialmente aos adultos e idosos, contrariando de certa forma a perspectiva intergeracional do programa. 
Figueiredo, 2009), e por exigências na consolidação dos convênios, como participação popular e universalização do acesso ao esporte e lazer, entre outras.

A despeito das questões técnicas levantadas que ocasionaram o surgimento do programa, bem como o seu desenho aqui apresentado, o PELC Projeto Social também teve seu surgimento relacionado a motivações políticas de demarcação de espaço e rupturas com gestões anteriores:

Nós tivemos um problema com o Ministério do Planejamento, porque eles identificaram, com precisão no meu modo de ver, o Segundo Tempo como uma continuidade do Esporte na Escola, do FHC, com mudança de nome, uma coisinha aqui e outra ali. E ficaram satisfeitos porque ai essa seqüência histórica estava garantida, mas ficaram incomodados com o Esporte e Lazer da Cidade que rompia com a lógica do Esporte Solidário. Então na verdade, na lógica do Ministério do Planejamento, o Esporte e Lazer da Cidade deveria acompanhar, na lógica da continuidade, o modelo conceitual do Esporte Solidário (GESTOR A, 2010).

As rupturas do PELC em relação ao Esporte Solidário estariam relacionadas, segundo o gestor, com a gestão participativa, a noção de pertencimento do programa à cidade, a abordagem intergeracional e o processo de formação do programa. Porém, não há como desconsiderar que o Esporte Solidário foi uma política do PSDB no governo Fernando Henrique Cardoso, e que o PT, por sua divergência histórica com o partido que o antecedeu no governo federal, dificilmente concordaria em avalizar que seu programa era uma continuidade do que já vinha sendo realizado por um grupo ideologicamente e politicamente oposto. Havia a nítida intenção de estabelecer uma ruptura com o governo anterior e deixar a marca da administração petista no subcampo político/burocrático do esporte e lazer no âmbito da administração pública federal, inclusive na disputa interna ao Ministério do Esporte entre PT e PCdoB:

Por que na configuração do PPA, o Ministro, o Secretário-executivo, o Secretário de Esporte Educacional (na época o atual Ministro, o Orlando), queriam nos convencer da necessidade de 
se manter um único programa, o nome do projeto social de Segundo Tempo. Eles queriam o Segundo Tempo Escolar e o Segundo Tempo Comunitário, e nós não arredamos o pé do Esporte e Lazer por conta de lógicas e por conta também de marcar nossa presença lá dentro (GESTOR A, 2010, grifos nossos).

No jogo estabelecido internamente à configuração do Ministério do Esporte, com características oligárquicas ${ }^{10}$ em benefício do $\mathrm{PCdoB}$, ter seu próprio programa, desvinculado de iniciativas anteriores e da intervenção direta do partido do ministro se configurou também como uma estratégia política do grupo vinculado ao PT na busca de um maior equilíbrio na balança de poder. Todavia, essa se mostrou uma jogada que teve seus efeitos limitados, uma vez que outras estratégias do grupo dominante no ministério garantiram a manutenção do jogo de uma maneira mais ou menos estável. A primeira delas era a questão orçamentária. Segundo os gestores entrevistados que estiveram no ministério durante grande parte da vigência do primeiro PPA da gestão Lula no governo federal, o orçamento do Ministério do Esporte respeitava uma lógica de distribuição de recursos que privilegiava a Secretaria Nacional de Esporte Educacional, e seu programa carro-chefe, o Segundo Tempo. Um orçamento muito menor era destinado à Secretaria Nacional de Esporte de Alto-rendimento, mas que ainda assim era cerca do dobro do que era destinado à SNDEL para o desenvolvimento de suas ações, incluindo aí o PELC Projeto Social.

O Ministro [...] teve quatro anos para com a caneta, com sua presença, dar toda e quase exclusiva visibilidade ao Segundo Tempo como projeto social, e nenhuma, absolutamente nenhuma visibilidade ao Esporte e Lazer da Cidade. Eu desafio você a pegar um discurso do [Ministro] durante o mandato dele onde ele faça menção do Esporte e Lazer da Cidade. E quando faz, se você fizer uma conta de tempo, de segundos que ele fala do Esporte e Lazer, e dos minutos que ele fala do Segundo Tempo (GESTOR A, 2010).

10-Em uma situação mais oligárquica, segundo Elias (2005), o equilíbrio de poder a favor do nível mais elevado é muito desproporcional, rígido e estável. 
Era, portanto uma restrição econômica, expressa no orçamento destinado à SNDEL, mas que passava também pela dimensão simbólica dos atos e aparições do Ministro do Esporte, agente consagrado pelo ato de nomeação e porta-voz legítimo do esporte nacional. Isso estaria facilitado por uma lógica de governo que solicitou a cada ministério que elegesse um programa prioritário, que no caso do Ministério do Esporte era o Programa Segundo Tempo.

Então nós tivemos essa dificuldade, de arriscar, de alcançar, de ganhar projeção. Tivemos que estabelecer uma luta de Davi contra Golias para conseguir peças publicitárias, na porrada, no facão [...] não tínhamos nada do Esporte e Lazer. Só havia alguma coisa do Segundo Tempo. [...] Cartazes, prospectos, foi uma briga muito grande (GESTOR A, 2010).

Dadas as circunstâncias, os agentes apontam que o grande legado do PELC Projeto Social foi justamente seu desenho, seu modelo conceitual, que teria rompido com o que já vinha sendo feito na administração pública federal do esporte e lazer. "Mas nós conseguimos, mesmo com todas essas dificuldades, fazer circular o modelo conceitual. Nós construímos um modelo de estrutura de equipamento esportivo e de lazer que hoje é referencia lá dentro do ministério, na Caixa Econômica [...]" (GESTOR A, 2010). Não se sabe ao certo se pela falta de condições ou por convicção teórica e política, serviria o PELC especialmente como um modelo, que a despeito do grupo que estivesse no governo, daria bases às políticas públicas de esporte e lazer. "[...] o PELC, ele são conceitos estruturantes de uma política. E esses conceitos então eles têm que ter, buscar as identidades, tem diretrizes, tem princípios, tem metas" GESTOR C, 2010). E a meta maior de gestão seria fazer com que os municípios adotassem esse modelo e não dependessem diretamente do governo federal. "[...] até em alguns casos o próprio município, pouquíssimos, parou de pedir, fazer convênio conosco e assumiu o PELC lá, como ele é, na sua cidade. Isso para mim é o máximo da evolução" (GESTOR C, 2010). Mas mesmo a circulação do modelo do PELC esbarrava na restrição orçamentária. Recorreu-se então a uma estratégia de subterfúgio ao impedimento orçamentário através da atuação política junto ao parlamento. 
Desenvolvemos, portanto um modelo conceitual, e nós não tínhamos recurso para implementar, mas tínhamos condições políticas de circular o modelo conceitual. Fizemos um bom trabalho junto ao Parlamento, ao Congresso, junto aos deputados da base aliada, divulgando esse modelo. E pra isso o trabalho do [Assessor do Ministério] foi fundamental. Como assessor ele fazia esse contato. Era dele a responsabilidade desse trânsito. O trabalho político nesse sentido foi bem feito (GESTOR A, 2010).

Através das emendas parlamentares o PELC acabou tendo certa expressão, mas não alcançou a escala almejada. Consta no relatório de gestão do PPA 2004-2007, por exemplo, que no ano de 2007 dois milhões de pessoas foram atendidas de forma sistemática pelo PELC. Somando-se os eventos promovidos esse número chegaria próximo de três milhões de pessoas, o que representa menos de $15 \%$ de taxa de atendimento da demanda de esporte recreativo e de lazer às pessoas em situação de vulnerabilidade social. No mesmo relatório consta como uma das principais realizações do PELC:

Ações educativas: com o funcionamento de 548 núcleos PELC/Vida Saudável, e chamada pública com 1.624 pleitos, sendo 172 encaminhados para conveniamento, pelos limites orçamentários das ações, e seleção pública e formação de multiplicadores do Programa (BRASIL, 2008, p. 28).

As justificativas para a pequena escala de atendimento do programa no relatório do PPA ressoam aquelas apontadas pelos gestores entrevistados: baixo orçamento, falta de recursos humanos na SNDEL e incapacidade das entidades proponentes para efetivação dos convênios. Em relação ao orçamento:

Tem havido dificuldade na obtenção de créditos orçamentários adicionais, uma vez que ações que receberam uma demanda, na chamada pública, de mais de $\mathrm{R} \$ 300$ milhões para um orçamento de R \$ 21 milhões, e não foi possível obter suplementação orçamentária. Em alguns momentos, a falta de limite financeiro do Ministério prejudicou o andamento dos pleitos. 
Emendas parlamentares liberadas quando se aproximava o final do exercício também prejudicaram a execução (BRASIL, 2008, p. 30).

Os recursos humanos, por sua vez, foram um entrave tanto dentro da equipe do Ministério quanto nas entidades conveniadas: "Em relação aos recursos humanos, a equipe é restrita para a grande demanda. A maior parte dos funcionários possui pouca qualificação profissional na área de atuação" (BRASIL, 2008, p. 30). Além disso, foram acusadas "dificuldades das entidades para organizar os projetos e documentos, de acordo com as exigências legais" (BRASIL, 2008, p. 29). De toda forma vale ressaltar que o PELC Projeto Social surge como um programa que objetiva atender a população em seu direito de acesso ao esporte e lazer, arquitetado por um grupo de agentes vinculados ao PT e ao campo científico/acadêmico, que teve uma pequena escala de atendimentos e que apresentou como grande legado o modelo conceitual que supostamente rompe com o que vinha sendo realizado no subcampo político/burocrático de esporte e lazer.

\section{Considerações finais}

No presente artigo buscamos analisar o surgimento e desenvolvimento do PELC, destacando seus aspectos técnico, conceitual e político. Tais reflexões nos encaminharam ao entendimento mais aprofundado do espaço social de produção das políticas públicas de esporte e lazer, o subcampo político/burocrático do esporte e lazer no Brasil, especialmente uma de suas estruturas - o Ministério do Esporte. Pudemos discorrer sobre as características únicas do PELC, que se difere de outros programas esportivos sociais por ter sido concebido a partir de experiências oriundas do subcampo cientifico/acadêmico das políticas públicas de esporte e lazer e das experiências de gestões municipais do Partido dos Trabalhadores (PT), e desenvolvido sob a égide de uma disputa política entre os dois partidos envolvidos na administração do Ministério do Esporte (PCdoB e PT). Cabe destacar que as experiências oriundas do subcampo cientifico/acadêmico das políticas públicas de esporte e lazer se manifestam nos documentos do programa, onde observamos consistência teórica no tratamento do esporte e lazer como direitos sociais e portanto objeto de políticas públicas, bem como no processo de concepção do programa, que contou 
com uma análise situacional pautada num autor reconhecido do campo científico/acadêmico. Esses procedimentos destoam substancialmente de outras iniciativas relativas às políticas públicas de esporte e lazer no Brasil, historicamente pautadas no empirismo (LINHALES, 1996; VERONEZ, 2005).

Dada a limitação de um trabalho dessa natureza, nos centramos em debater o PELC Projeto Social - denominação por nós utilizada para diferenciar a ação "Funcionamento de núcleos do PELC" das demais atividades do PELC -, sublinhando as motivações técnicas do seu surgimento (os "nós" detectados no planejamento da SNDEL), os aspectos conceituais (presentes no desenho formal do programa), e os aspectos políticos (a limitação orçamentária e a estratégia de sobrevivência efetiva do programa por meio de emendas parlamentares) presentes na arena política de desenvolvimento de tal programa. Compete observar que o programa experimentou mudanças na transição do primeiro mandato (2003-2006) para o segundo mandato (2007-20010) do Governo Lula. Nossa análise, nesse sentido, se dedicou prioritariamente aos primeiros momentos de concepção e gestão do PELC, ou seja, ao início do primeiro mandato do Governo Lula.

Podemos destacar que o PELC Projeto Social apresenta algumas rupturas em relação a outros projetos esportivo-sociais, especialmente no que diz respeito ao tratamento intergeracional nas intervenções, e na elaboração pautada em um diagnóstico situacional das políticas públicas de esporte e lazer no Brasil. Esse último ponto destoa bastante do histórico de desenvolvimento das políticas públicas no Brasil, e pode ser considerado um grande avanço. Todavia, e entendendo que a fala dos agentes por vezes transparece certa ufania em relação ao programa, pudemos constatar também através dos documentos oficiais, que o PELC foi prejudicado em sua escala de atendimentos pela restrição orçamentária. Tal restrição estaria relacionada especialmente ao aspecto político na disputa interna entre dois partidos que co-existiram na administração do Ministério do Esporte. A própria denominação do programa foi um retrato da disputa entre os dois grupos, onde prevaleceu a vontade de um, mas o outro usou dos meios acessíveis para desprestigiá-lo. Finalmente podemos observar nos documentos e fontes oficiais de informação, um desenho conceitual do programa, que só pode ser integralmente compreendido se obser- 
vado a luz da arena política que deu sentido e concretude a esse desenho.

\title{
TECHNICAL, CONCEPTUAL AND POLITICAL ASPECTS OF APPEA- RANCE AND DEVELOPMENT OF PROGRAM SPORT AND LEISURE OF THE CITY
}

\begin{abstract}
In this paper we analyze the process of development and implementation of the Program Sport and Leisure of the City (PELC), considering its technical, conceptual and political, highlighting the advances, limitations and contradictions inherent PELC in view of their social space production subfield. To this end, we resort to semi-structured interviews with agents of the Ministry of Sport managers directly related to the process of creation, implementation and development of PELC as well as desk review of certain documents relating to the ministry relating to PELC. We hold that the PELC differs from other social sports programs have been designed by experience derived from the subfield scientific / academic public policy for sport and leisure and experiences of municipal administrations of the Workers Party (PT), and developed under the aegis of a political dispute between the two parties who administered the Sports Ministry.

Keywords: Public Policies. Sports. Leisure. Politics.

\section{ASPECTOS TÉCNICOS, CONCEPTUAIS Y POLÍTICOS DEL SURGIMI- ENTO Y DESARROLLO DE LO PROGRAMA DEPORTE Y LA RECREA- CIÓN DE LA CIUDAD}

\section{Resumen}

En este trabajo se analiza el proceso de desarrollo e implementación del Programa Deporte y la Recreación de la Ciudad (PELC), inherente técnico, conceptual y político, destacando los avances, las limitaciones y contradicciones, dado el espacio social de su producción, el subcampo político / burocrático deportes y ocio. Para ello, se recurre a entrevistas semi-estructuradas con los agentes del Ministerio de gerentes de deportes relacionados directamente con el proceso de creación, implementación y desarrollo de PELC así como la revisión documental de determinados documentos del ministerio relativos a la PELC. Sostenemos que la PELC se diferencia de otros programas de deportes sociales han sido diseñados por la experiencia derivada de la subcampo científico / académico de políticas públicas para el deporte y el ocio y las experiencias de las administraciones municipales del Partido de los Trabajadores (PT), y se desarrolló bajo la marco de una disputa política entre los dos partidos que administraron el Ministerio de Deportes.

Palabras clave: Políticas Públicas. Deportes. Actividades Recreativas. Política. 


\section{Referências}

AMARAL, S. C. F; PEREIRA, A. P. C. Reflexões sobre a produção em políticas públicas de Educação Física, esporte e lazer. Revista Brasileira de Ciências do Esporte, Campinas, v. 31, n. 1., set., 2009.

AREIAS, K. V. et al. As políticas públicas de lazer na mediação entre estado e sociedade: possibilidades e limitações. In: CONGRESSO BRASILEIRO DE CIÊNCIAS DO ESPORTE, 16., 2009, Salvador; CONGRESSO INTERNACIONAL DE CIÊNCIAS DO ESPORTE, 3., 2009, Salvador. Anais... Salvador: Colégio Brasileiro de Ciências do Esporte, 2009.

BOURDIEU, P. A casa do rei à razão de Estado: um modelo da gênese do campo burocrático. In: WACQUANT, L (Org.). O mistério do ministério: Pierre Bourdieu e a política democrática. Rio de Janeiro: Revan, 2005. p. 41-70.

BRASIL. Ministério do Esporte. Programa Esporte e Lazer da Cidade. Disponível em <http://portal.esporte.gov.br/sndel/esporteLazer/default.jsp>. Acesso em 29 set. 2010. Não paginado.

. Ministério do Esporte. Estratégia 1 - Ação Educativa. Disponível em <http://www.esporte.gov.br/sndel/esporteLazer/estrategia1.jsp>. Acesso em 03 fev. 2011. Não paginado.

Ministério do Planejamento, Orçamento e Gestão. Secretaria de Orçamento Federal. Manual Técnico de Orçamento MTO-02: instruções para elaboração da proposta orçamentária da União para 2004. Brasília: [s. n.], 2003. Disponível em <https://www.portalsof.planejamento.gov.br/bib/publicacoes/MTO2004.pdf $>$. Acesso em 19 dez. 2010.

. Ministério do Planejamento. Relatório de gestão do PPA 2004-2007. Brasília: [s. n.], 2008. Disponível em $<$ http:/www.camara.gov.br/internet/comissao/index/mista/orca/ppa/ppa_2004_2007_avaliacao2008/vol1t1/0_indice_apresentacao.pdf $>$. Acesso em 20 jan. 2011.

CASTELLANI FILHO, L. (Org.) Gestão pública e política de lazer: a formação de agentes sociais. São Paulo: Autores Associados, 2007. 
COSTA JÚNIOR, E. F. da. O PELC em São Gonçalo: uma proposta de lazer no Criam vivenciada numa perspectiva da diversidade dos interesses culturais. In: CONGRESSO BRASILEIRO DE CIÊNCIAS DO ESPORTE, 16., 2009, Salvador; CONGRESSO INTERNACIONAL DE CIÊNCIAS DO ESPORTE, 3., 2009, Salvador. Anais... Salvador: Colégio Brasileiro de Ciências do Esporte, 2009.

ELIAS, N. Introdução à sociologia. São Paulo: Edições 70, 2005.

EWERTON, A. N.; FERREIRA, H. I. Análise da formação profissional no Programa Esporte e Lazer da Cidade (PELC): o olhar dos agentes sociais. In: CONGRESSO BRASILEIRO DE CIÊNCIAS DO ESPORTE, 16., 2009, Salvador; CONGRESSO INTERNACIONAL DE CIÊNCIAS DO ESPORTE, 3., 2009, Salvador. Anais... Salvador: Colégio Brasileiro de Ciências do Esporte, 2009.

FIGUEIREDO, P. O. F. de N. Política e formação: o Programa Esporte e Lazer da Cidade no Distrito Federal e entorno. 2009. $136 \mathrm{f}$. Dissertação (Mestrado em Educação Física)-Faculdade de Educação Física, Universidade de Brasília, Brasília, 2009.

FREY, K. Políticas públicas: um debate conceitual e reflexões referentes à prática da análise de políticas públicas no Baril. Planejamento e Políticas Públicas, Brasília, n. 21, p. 211-259, jun., 2000.

GESTOR A. Entrevista sobre o Programa Esporte e Lazer da Cidade e o desenvolvimento de políticas no Ministério do Esporte. [Campinas], Universidade Estadual de Campinas, 27 out. 2010. Entrevista concedida a Fernando Augusto Starepravo.

GESTOR B. Entrevista sobre o Programa Esporte e Lazer da Cidade e o desenvolvimento de políticas no Ministério do Esporte. [Pelotas], Universidade Federal de Pelotas, 29 nov. 2010. Entrevista concedida a Fernando Augusto Starepravo.

GESTOR C. Entrevista sobre o Programa Esporte e Lazer da Cidade e o desenvolvimento de políticas no Ministério do Esporte. [São Bernardo], Universidade Metodista de São Paulo, 26 mar.2010. Entrevista concedida a Fernando Augusto Starepravo.

GESTOR D. Entrevista sobre o Programa Esporte e Lazer da Cidade e o desenvolvimento de políticas no Ministério do Esporte. 
[São Bernardo], Universidade Metodista de São Paulo, 25 mar. 2010. Entrevista concedida a Fernando Augusto Starepravo.

HEY, A. P. Esboço de uma sociologia do campo acadêmico: a educação superior no Brasil. São Carlos: EdUFSCar, 2008.

HÚNGARO, V.; MELO, L. L. de. A formação continuada no programa esporte e lazer da cidade: emancipação ou reprodução. In: CONGRESSO BRASILEIRO DE CIÊNCIAS DO ESPORTE, 15., 2007, Salvador; CONGRESSO INTERNACIONAL DE CIÊNCIAS DO ESPORTE, 2., 2007, Recife. Anais... Recife: Colégio Brasileiro de Ciências do Esporte, 2007.

LIÁO JÚNIOR, R.; SAMPAIO, J. O.; BEHMOIRAS, D. C. Controle social na perspectiva do Programa Esporte e Lazer da Cidade. In: CONGRESSO BRASILEIRO DE CIÊNCIAS DO ESPORTE, 16. 2009, Salvador; CONGRESSO INTERNACIONAL DE CIÊNCIAS DO ESPORTE, 3., 2009, Salvador. Anais... Salvador: Colégio Brasileiro de Ciências do Esporte, 2009.

LINHALES, M. A. A trajetória política do esporte no Brasil: interesses envolvidos, setores excluídos. 1996. 242f. Dissertação (Mestrado em Ciência Política)-Faculdade de Filosofia e Ciências Humanas, Universidade Federal de Minas Gerais, Belo Horizonte, 1996.

MENDES, R. O que é lazer? Uma análise dos pleitos de Minas Gerais do Programa Esporte e Lazer da Cidade em 2007. 2009. 164f. Dissertação (Mestrado em Educação Física)-Universidade Federal de Juiz de Fora/Universidade Federal de Viçosa, Juiz de Fora, 2009.

SAGRILLO, D. R.; BACCIN, E. V. C.; BOTH, V. J. Políticas públicas de esporte e lazer: análise do programa esporte e lazer da cidade. In: CONGRESSO BRASILEIRO DE CIÊNCIAS DO ESPORTE, 15., 2007, Salvador; CONGRESSO INTERNACIONAL DE CIÊNCIAS DO ESPORTE, 2., 2007, Recife. Anais... Recife: Colégio Brasileiro de Ciências do Esporte, 2007.

SUASSUNA, D. M. F. de A. O Programa Esporte e Lazer da Cidade: a política de formação para o trabalho e o papel dos agentes sociais. In: CONGRESSO BRASILEIRO DE CIÊNCIAS DO ESPORTE, 16. 
2009, Salvador; CONGRESSO INTERNACIONAL DE CIÊNCIAS DO ESPORTE, 3., 2009, Salvador. Anais... Salvador: Colégio Brasileiro de Ciências do Esporte, 2009.

VERONEZ, L. F. Quando o Estado joga a favor do privado: as políticas de esporte após a Constituição Federal de 1988. 2005. 386f. Tese (Doutorado em Educação Física)-Faculdade de Educação Física, Universidade Estadual de Campinas, Campinas, 2005.

Recebido em: 18/07/2012

Revisado em: 10/10/2012

Aprovado em: 03/12/2012

Endereço para correspondência

fernando.starepravo@hotmail.com

Fernando Augusto Starepravo

Universidade Estadual de Maringá

Centro de Ciências Biológicas, Departamento de Educação Física.

Avenida Colombo, 5.790 - Campus Universitário

Centro

87020-900 - Maringa, PR - Brasil 